\title{
Long-term complications after stent assist coiling dependent on clopidogrel response
}

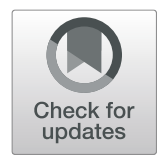

Kenji Shoda ${ }^{*}$, Yukiko Enomoto, Yusuke Egashira, Takamasa Kinoshita, Daisuke Mizutani and Toru Iwama

\begin{abstract}
Background: Dual antiplatelet therapy (DAPT) is necessary for stent assisted coiling. However, long term use of DAPT has a potential risk of hemorrhagic events. We aimed to examine the relationship between clopidogrel reactivity and complications.

Methods: Patients who underwent stent assisted coiling for unruptured aneurysms or previously treated aneurysms and received periprocedural DAPT in our institution between August 2011 to March 2020 were included. Platelet reactivity for clopidogrel was measured by VerifyNow assay system, and we defined the cut off value of P2Y12 Reaction Units (PRU) at 208 and classified patients as hypo-responders (PRU $\geqq 208)$ or responders $(P R U<208)$. The rates of hemorrhagic and thrombotic events within 30 days (acute phase) and 30 days after the procedure (delayed phase) were compared between the two groups. Furthermore, changes in hemoglobin levels were measured before and after the procedure and at chronic stages (1 to 6 months thereafter).

Results: From 61 patients included in this study, 36 patients were hypo-responders and 25 patients were responders. Hemorrhagic events occurred $8.0 \%$ only in responders in the acute phase $(p=0.16)$, and $2.78 \%$ in hyporesponders and $20.0 \%$ in responders in the delayed phase $(p=0.037)$. Changes in hemoglobin levels before and after the procedure were $1.22 \mathrm{~g} / \mathrm{dl}$ in hypo-responders and $1.74 \mathrm{~g} / \mathrm{dl}$ in responders $(p=0.032)$ while before the procedure and chronic stages they were $0.39 \mathrm{~g} / \mathrm{dl}$ in hypo-responders and $1.39 \mathrm{~g} / \mathrm{dl}$ in responders $(p<0.01)$. Thrombotic events were not significantly different between the two groups.

Conclusion: Long term use of DAPT after stent assisted coiling is related to hemorrhagic events in the delayed phase. Preventing for hemorrhagic events, the duration of DAPT should be carefully considered in clopidogrel responders.
\end{abstract}

Keywords: Dual antiplatelet therapy, Stent assisted coiling, Hemorrhagic events, Chronic phase

\section{Background}

In the treatment of intracranial aneurysms, adjunctive techniques such as the balloon assist technique or stent assisted coiling are not only effective for wide-necked aneurysms but also decrease recurrence rates. Periprocedural dual antiplatelet therapy (DAPT) is necessary to reduce increasing thrombotic complications as the procedure complexity augments [1-3]. However, the

\footnotetext{
* Correspondence: sho_ken@gifu-u.ac.jp

Department of Neurosurgery, Gifu University Graduate School of Medicine, 1-1 Yanagido, Gifu, Gifu 501-1194, Japan
}

duration of DAPT varied greatly among previous studies, and an optimal duration remains unknown [4-6], despite long-term DAPT use having a potential risk for hemorrhagic events. Before the procedure, measuring platelet reactivity is recommended, since platelet reactivity shows a high level of interindividual variability, particularly in the case of clopidogrel, which must be converted to a biologically active metabolite by cytochrome P450 enzymes (CYP) [7].

This study aimed to clarify the relationship between clopidogrel responses and complications. We measured platelet aggregation activity using VerifyNow

(c) The Author(s). 2021 Open Access This article is licensed under a Creative Commons Attribution 4.0 International License, which permits use, sharing, adaptation, distribution and reproduction in any medium or format, as long as you give appropriate credit to the original author(s) and the source, provide a link to the Creative Commons licence, and indicate if changes were made. The images or other third party material in this article are included in the article's Creative Commons licence, unless indicated otherwise in a credit line to the material. If material is not included in the article's Creative Commons licence and your intended use is not permitted by statutory regulation or exceeds the permitted use, you will need to obtain permission directly from the copyright holder. To view a copy of this licence, visit http://creativecommons.org/licenses/by/4.0/ The Creative Commons Public Domain Dedication waiver (http://creativecommons.org/publicdomain/zero/1.0/) applies to the data made available in this article, unless otherwise stated in a credit line to the data. 
(Accumetrics, San Diego, CA, USA) and investigated its association to clopidogrel responses and the occurrence of hemorrhagic and thrombotic events within 30 days of stent assisted coiling and 30 days after stent assisted coiling.

\section{Methods}

\section{Study population}

There were 77 aneurysms treated with stent assisted coiling for unruptured intracranial aneurysms $(n=67)$ and previously treated aneurysms $(n=10)$ using DAPT from August 2011 to March 2020 at our institution. Whole blood samples were obtained from patients at the time of the initial femoral artery puncture to measure platelet reactivity by VerifyNow. Patients who could not be measured platelet aggregation activity measurements by VerifyNow before the procedure $(n=9)$, and those who discontinued DAPT at least 1 month after the procedure $(n=7)$ were excluded. According to American College of Cardiology Foundation (ACCF)/ American Heart Association (AHA) 2011 guidelines [8], we defined the cut off value of P2Y12 Reaction Units (PRU) at 208' and classified patients as hypo-responders (PRU $\geqq 208)$ or responders $(\mathrm{PRU}<208)$. We investigated hemorrhagic and thrombotic events within 30 days after the procedure (acute phase) and between one to 6 months after the procedure (delayed phase). Hemorrhagic events were defined as major bleeding events by the International Society of Thrombosis and Hemostasis [9], and thrombotic events were defined as symptomatic hyperintensity lesions on diffusion weighted imaging or transit ischemic attacks. In addition, we tracked changes in hemoglobin $(\mathrm{Hb})$ levels from prior to the procedure to right afterwards and in chronic stages (time of hemorrhagic event or latest visit under DAPT treatment in the delayed phase). Demographic and clinical data collected included age, sex, smoking history, previously treated aneurysms, and the presence of comorbid hypertension, hyperlipidemia, diabetes mellitus, or chronic renal failure. This study was approved by the ethics committee of Gifu University Graduate School of Medicine (No. 2019184). Due to the retrospective nature of the study, the need for informed written consent was waived by the ethics committee of Gifu University Graduate School of Medicine.

\section{Antiplatelet therapy}

Antiplatelet drugs were started 7 days before the procedure, and these usually included clopidogrel $75 \mathrm{mg}$ and aspirin $100 \mathrm{mg}$. On the morning of the procedure day, we measured platelet reactivity by Light Transmittance Aggregometry. And just before the procedure, final platelet reactivity was measured by VerifyNow. After inserting the sheath, we injected heparin aiming for an activated clotting time of $250-300 \mathrm{~s}$. After the procedure, we initiated continuous intravenous administration of 10,000 units of heparin for 2 days. Six months after the procedure, we moved from DAPT to single antiplatelet therapy. However, if hemorrhagic events occurred, DAPT was discontinued from 1 to 3 months.

Table 1 Baseline demographics

\begin{tabular}{llll}
\hline & Hypo-responders $(\boldsymbol{n}=\mathbf{3 6})$ & Responders $(\mathbf{n}=\mathbf{2 5})$ & $\boldsymbol{p}$ value \\
\hline Age (years) & $62.4 \pm 2.24$ & $62.6 \pm 2.38$ & 0.97 \\
Male sex (\%) & $10(27.8)$ & $7(28.0)$ & 1 \\
PRU & $262.4 \pm 7.36$ & $142.1 \pm 8.59$ & 0.01 \\
ARU & $489.1 \pm 11.7$ & $482.5 \pm 16.1$ & 0.73 \\
Body mass index & $22.5 \pm 0.61$ & $22.3 \pm 0.61$ & 0.85 \\
Smoking (\%) & $9(25.0)$ & $6(24.0)$ & 1 \\
Previously treated aneurysms (\%) & $5(13.9)$ & $5(20.0)$ & 0.73 \\
Blood sample & & & 0.31 \\
Hb (mg/dl) & $13.1 \pm 0.22$ & $13.5 \pm 0.29$ & 0.08 \\
Platelet (10 $/ \mu L)$ & $21.9 \pm 0.99$ & $24.8 \pm 1.27$ & 0.42 \\
PT-INR & $0.94 \pm 0.01$ & $0.92 \pm 0.01$ & \\
comorbidities & $19(52.8)$ & & 0.11 \\
Hypertension (\%) & 0 & $20(76.0)$ & 0.16 \\
Diabetes mellitus (\%) & $15(41.7)$ & $17(64.0)$ & 0.12 \\
Hyperlipidemia (\%) & $5(13.89)$ & $3(12.0)$ & 1 \\
Chronic renal failure (\%) & & \\
\hline
\end{tabular}

Continuous variables are presented as average (mean $\pm S E$ ). Categorical variables are presented as number of patients (percentage). PRU P2Y12 Reaction Units; $A R U$ Aspirin Reaction Units; $H b$ Hemoglobin; PT-INR prothrombin time international normalized ratio 


\section{Statistical analysis}

All statistical analyses were performed using commercially available software (JUMP 14; SAS Institute, Cary, NC, USA). The student's t-test was used for comparisons with continuous variables and the Fisher exact test for comparisons with categorical variables. Significant differences were defined as a $P$ value $p<0.05$.

\section{Result}

Sixty-one patients were enrolled in this study. Of those, 36 were hypo-responders (mean PRU $262.4 \pm 44.1$ ) while 25 were responders (mean PRU 141.4 \pm 42.3 ). Regarding changes in $\mathrm{Hb}$ levels, 14 patients did not have a blood test in our hospital during the chronic phase, therefore 47 patients were evaluated. (hypo-responders: $n=26$, responders: $n=21$ ) Demographic and clinical data and are shown in Table 1. There are no significant differences between the two groups. There were 21 Enterprise, 10 Neuroform, and 30 LVIS stents used in this study. The rate of hemorrhagic events in the acute phase was not significantly different between the two groups $(p=0.16)$ (Fig. 1A, Table 2). Two patients in the responders group suffered from gastrointestinal hemorrhage. Furthermore, hemorrhagic events in the delayed phase were more frequently observed in responders $(p=0.037)$ (Fig. 1A, Table 3). Thrombotic events occurred in two patients (5.6\%) in the hypo-responders group and three patients $(12.0 \%)$ in the responders group during the acute phase $(p=0.39)$ (Fig. 1B). Thrombotic events in the delayed phase occurred one patient in the hypo-responders group (Fig. 1B), and one patient in the hypo-responders group showed stent stenosis by follow up angiography 6 months after the procedure. The difference in $\mathrm{Hb}$ levels from before to after the procedure was higher in responders than in hypo-responders $(1.74 \mathrm{~g} / \mathrm{dl}$ vs $1.22 \mathrm{~g} / \mathrm{dl}$, $p=0.032$ ), as was the change in $\mathrm{Hb}$ levels from before the procedure and the chronic stage $(1.39 \mathrm{~g} / \mathrm{dl}$ vs $0.39 \mathrm{~g} /$ $\mathrm{dl}, p<0.01$ ) (Fig. 1C, Table 4). Patients who were changed earlier to single antiplatelet therapy due to hemorrhagic events did not develop neither hemorrhagic nor thrombotic events in the delayed phase.

\section{Discussion}

In our study, there was no difference in the incidence of thrombotic events between the two groups, although responders had hemorrhagic events at a significantly higher rate. In interventions for coronary arteries, the AHA/ American Stroke Association (ASA) guideline recommends patients to continue DAPT including P2Y12 inhibitors after stenting [10], and in the neuroendovascular treatment area, antiplatelet drugs are also employed for preventing thrombotic complications. However, the optimal duration of DAPT after stent assist coiling is uncertain. There are some reports on the

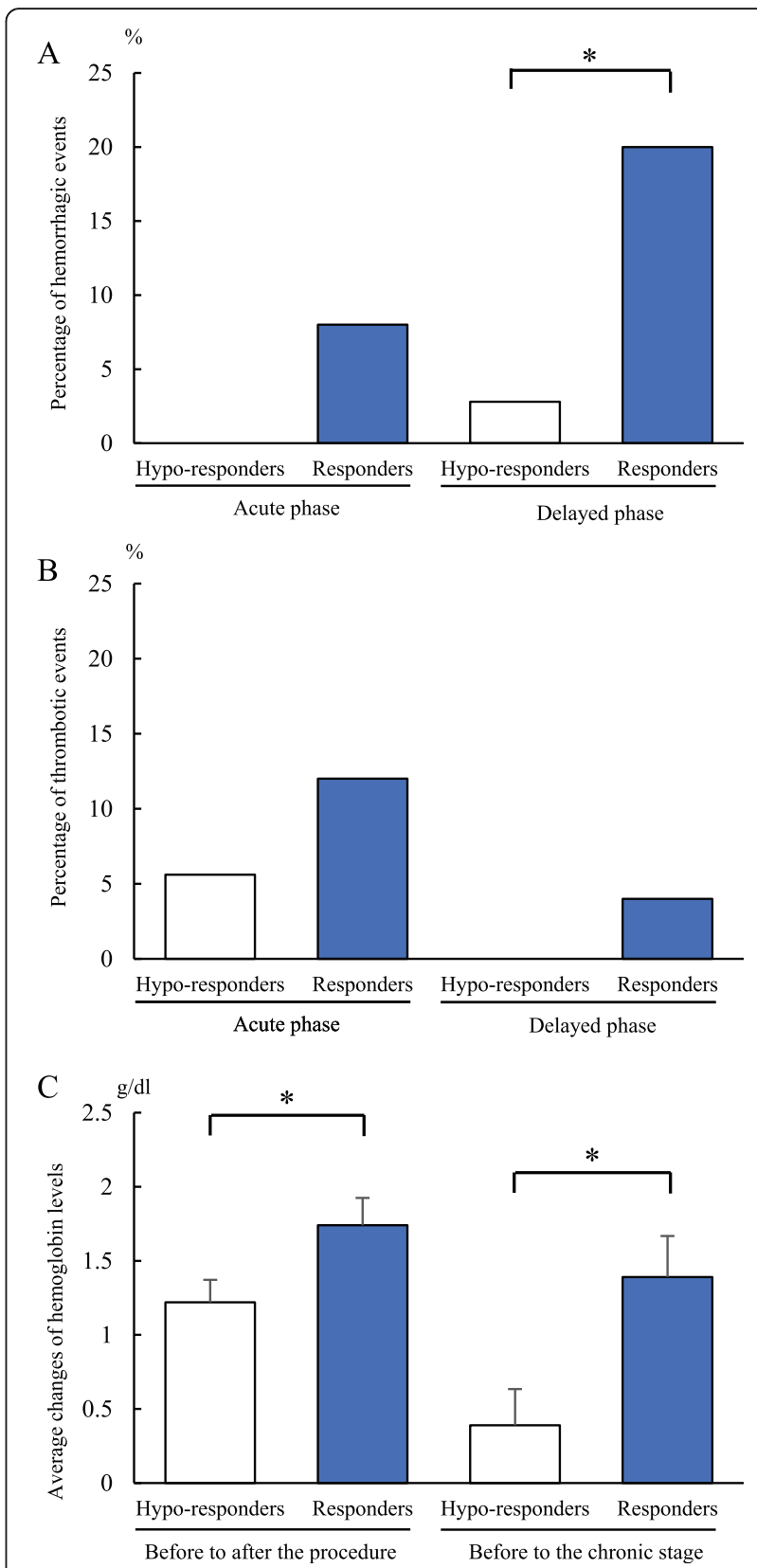

Fig. 1 A shows the percentage of hemorrhagic events in the acute phase and the delayed phase, and $\mathbf{B}$ shows thrombotic events (hypo-responders: $n=36$, responders: $n=25$ ). C shows average changes of hemoglobin levels before the procedure to after and before the procedure to the chronic stage (hypo-responders: $n=26$, responders: $n=21$ ). Each column and bar represent the mean $\pm S E$. All of them compared hypo-responders and responders. ${ }^{*}=p<0.05$ by student's t-test

timing and risk of thrombotic events, for instance, Matsumoto et al. reported that thrombotic events after the procedure are most likely to occur within 40 days after stent assisted coiling even if patients receive DAPT [11]. Furthermore, Song et al. reported that blood vessel tortuosity and large parent vessel size lead to incomplete 
Table 2 Complications after stent assist coiling during the acute and delayed phases

\begin{tabular}{lllll}
\hline Events & & Hypo-responders $(\mathbf{n}=\mathbf{3 6})$ & Responders $(\mathbf{n}=\mathbf{2 5})$ & $\boldsymbol{p}$ value \\
\hline Hemorrhagic events & Acute phase & 0 & $2(8.0 \%)$ & 0.16 \\
& Delayed phase & $1(2.8 \%)$ & $5(20.0 \%)$ & 0.037 \\
Thrombotic events & Acute phase & $2(5.6 \%)$ & $3(12.0 \%)$ & 0.39 \\
& Delayed phase & 0 & $1(4.0 \%)$ & 0.41
\end{tabular}

stent apposition, becoming a risk factor of thrombotic complications [12].

Clopidogrel is an antiplatelet drug of widespread application. In Japan, it is administered in approximately $80 \%$ of cases in the perioperative period of neurovascular treatments [13]. Clopidogrel is a prodrug which needs to be converted into an active metabolite by CYP. Although CYP2C19 is the major enzyme involved in this process, its genetic variants can affect individual clopidogrel responses. Therefore, measuring platelet reactivity before the procedure is relevant. There are some methods to measure platelet functions, VerifyNow being one of the major points of care platelet reactivity analysis tools and employed on large clinical trials $[14,15]$. Some studies have shown an association of hyper-responders to clopidogrel hemorrhagic events while hypo-responders are associated with thrombotic events, although a clear cutoff value has not been defined for neuroendovascular treatments and this value differed among studies [1622]. A previous report involving the use of the Pipeline indicated that the ideal PRU value for avoiding both hemorrhagic and thrombotic events was between 70 and 150 [22]. Based on the ACCF/AHA 2011 guideline [8], we defined 208 as cutoff value and investigated hemorrhagic and thrombotic events both in the acute and delayed phase. In this study, the occurrence of thrombotic events was not significantly different between the groups, although hemorrhagic events frequently occurred in responders. In addition, $\mathrm{Hb}$ levels decreased more from before until after the procedure and during chronic stages in responders than in hyporesponders. Despite not meeting the criteria of International Society of Thrombosis and Hemostasis for major bleeding [9], some patients complained of subcutaneous bleeding, epistaxis, or hematuria, which could be associated with low $\mathrm{Hb}$ levels in the chronic stage.

Although some studies of stent assisted coiling reported an association of hemorrhagic and thrombotic events with PRU values in the acute phase [17-21], there are few studies of an association between platelet reactivity and these events in the delayed phase after stent assisted coiling. Goh et al. reported that evaluating hemorrhagic events up to 6 weeks after endovascular stenting treatment indicated that patients with $>72 \%$ PRU inhibition had more major bleeding than those with PRU $<72 \%$ [23]. Song et al. also referred to an association between clopidogrel response and thrombotic events in the delayed phase [21]. These authors reported that thrombotic events, symptomatic and asymptomatic ischemic stroke with positive findings on brain MRI in the territory of the treated aneurysm, or a transient ischemic attack more than 30 days after stent assisted coiling were not significantly correlated with PRU values. In agreement with this finding, our study showed a relationship between PRU values and hemorrhagic events, but not thrombotic events, in the delayed phase. Consequently, PRU appears to be more associated with hemorrhagic events in the delayed phase.

A previous study on DAPT duration in other treatment areas, reported that long-term DAPT use after ischemic stroke or after previous transient ischemic attacks increased the risk of major to life-threatening bleeding [24]. In addition, a recent study showed that, among patients undergoing coronary stents, 1 month of DAPT followed by clopidogrel single antiplatelet therapy resulted in a significantly lower rate of a composite of cardiovascular and bleeding events compared to 12

Table 3 Hemorrhagic events in the delayed phase

\begin{tabular}{llllll}
\hline Case & PRU & Response & Hemorrhagic event & Hb change $(\mathbf{g} / \mathbf{d l})$ & After the procedure \\
\hline 1 & 296 & Hypo-responder & Gastrointestinal bleeding & 5 & 2 months \\
2 & 94 & Responder & Hematuria & 2.2 & 4 months \\
3 & 123 & Responder & Gastrointestinal bleeding & 2.2 & 3 months \\
4 & 175 & Responder & Intracranial hemorrhage & 4.5 & 2 months \\
5 & 197 & Responder & Genital bleeding & 3.5 & 1 month \\
6 & 206 & Responder & Hemorrhagic infarction & 2.3 & 2 months \\
\hline
\end{tabular}


Table $4 \mathrm{Hb}$ change from before until after the procedure and the chronic stage

\begin{tabular}{llll}
\hline Hb change & Hypo-responders $(\mathbf{n}=\mathbf{2 6})$ & Responders $(\mathbf{n}=\mathbf{2 1})$ & $\boldsymbol{p}$ value \\
\hline Before to after the procedure $(\mathrm{g} / \mathrm{d} \mathrm{l})$ & $1.22 \pm 0.15$ & $1.74 \pm 0.18$ & 0.032 \\
Before to chronic stage $(\mathrm{g} / \mathrm{d})$ & $0.39 \pm 0.24$ & $1.39 \pm 0.28$ & $<0.01$ \\
\hline
\end{tabular}

Continuous variables are presented as average (mean $\pm \mathrm{SE}$ ). $\mathrm{Hb}$ hemoglobin. 1

months of DAPT with clopidogrel and aspirin. Thus, a shorter DAPT duration after stenting may be more beneficial compared to long-term DAPT [25]. Even in cases of hemorrhagic events where DAPT was changed to single antiplatelet therapy 1 to 3 months before usual, there were no thrombotic events. Patients treated for aneurysm with neuro interventions are usually younger and thus, have fewer arteriosclerosis risk factors compared to patients treated with cerebrovascular or coronary revascularization [21], maybe reducing the risk of thrombotic events [23].

In our study, we found that clopidogrel responders had an increased risk of hemorrhagic events in the delayed phase, and PRU is useful for the prediction of hemorrhagic events. Although DAPT is necessary for thrombotic event prevention, hemorrhagic risk and DAPT duration should be carefully considered in clopidogrel responders. Further studies are needed to determine the ideal duration of DAPT administration.

\section{Limitations}

There are several limitations to this study. First, this study is retrospective in nature, and hence subjected to potential confounding effects and bias. Second, we evaluated only 61 cases for postoperative complications. Therefore, it is quite possible that the statistical power of this study is insufficient to detect small differences. Third, it is known that clopidogrel response may be delayed conversion to clopidogrel hyper response [26]. We measured PRU only during the preoperative period, and thus, our evaluation may not be accurate.

\section{Conclusion}

Our study demonstrates that long-term DAPT use after stent assisted coiling can lead to hemorrhagic events. Both hemorrhagic events in the delayed phase and decreased hemoglobin levels are associated with clopidogrel responses. Further, we showed that thrombotic events are not associated with PRU. DAPT duration should be carefully considered in clopidogrel responders.

\section{Abbreviations}

DAPT: Dual antiplatelet therapy; PRU: P2Y12 reaction units; CYP: Cytochrome P450 enzymes; ACCF: American College of Cardiology Foundation; AHA: American Heart Association; Hb: Hemoglobin; ASA: American Stroke Association; ARU: Aspirin reaction unit; PT-INR: Prothrombin time international normalized ratio; APTT: Activated partial thromboplastin time

Acknowledgements

Not applicable.

\section{Authors' contributions}

All authors contributed to the study conception and design. Material preparation, data collection and analysis were performed by [KS], [YE1], [YE2], [TK] [DM] and [TI]. The first draft of the manuscript was written by [KS] and all authors commented on previous versions of the manuscript. All authors read and approved the final manuscript.

\section{Funding}

Not applicable.

\section{Availability of data and materials}

The datasets during the current study available from the corresponding author on reasonable request.

\section{Declarations}

Ethical approval and consent to participate

This study was approved by the ethics committee of Gifu University Graduate School of Medicine (No. 2019-184). Due to the retrospective nature of the study, the need for informed written consent was waived by the ethics committee of Gifu University Graduate School of Medicine.

\section{Consent for publication}

Not applicable.

\section{Competing interests}

The authors declare that they have no competing interest.

Received: 8 January 2021 Accepted: 7 June 2021

Published online: 28 June 2021

References

1. Piotin M, Blanc R, Spelle L, et al. Stent-assisted coiling of intracranial aneurysms: clinical and angiographic results in 216 consecutive aneurysms. Stroke. 2010;4:110-5.

2. Takigawa T, Suzuki K, Sugiura $Y$, Suzuki R, Takano I, Shimizu N, et al. Thromboembolic events associated with single balloon-, double balloon-, and stent-assisted coil embolization of asymptomatic unruptured cerebral aneurysms: evaluation with diffusion-weighted MR imaging. Neuroradiology. 2014:56(12):1079-86. https://doi.org/10.1007/s00234-014-1421-4.

3. Kanaan $\mathrm{H}$, Jankowitz $B$, Aleu A. In-stent thrombosis and stenosis after neckremodeling device-assisted coil embolization of intracranial aneurysms. Neurosurgery. 2010;67(6):1523-32. https://doi.org/10.1227/NEU.0b013e3181 f8d194.

4. Rossen JD, Chalouhi N, Wassef SN, Thomas J, Abel TJ, Jabbour PM, et al. Incidence of cerebral ischemic events after discontinuation of clopidogrel in patients with intracranial aneurysms treated with stent-assisted techniques. J Neurosurg. 2012;117(5):929-33. https://doi.org/10.3171/2012.8.JNS12185.

5. Kim T, Kim CH, Kang SH, et al. Relevance of antiplatelet therapy duration after stent-assisted coil embolization for Unruptured intracranial aneurysms. World Neurosurg. 2018;116:699-708.

6. Hwang G, Kim JG, Song KS, Lee YJ, Villavicencio JB, Suroto NS, et al. Delayed ischemic stroke after stent-assisted coil placement in cerebral aneurysm: characteristics and optimal duration of preventative dual antiplatelet therapy. Radiology. 2014;273(1):194-201. https://doi.org/10.1148/radiol.1414 0070

7. Hulot JS, Bura A, Villard E, Azizi M, Remones V, Goyenvalle C, et al. P450 2C19 loss-of-function polymorphism is a major determinant of Clopidogrel responsiveness in healthy subjects. Blood. 2006;108:2244-7. https://doi.org/1 0.1182/blood-2006-04-013052.

8. Wright RS, Anderson JL, Adams CD, et al. 2011 ACCF/AHA focused update of the Guidelines for the Management of Patients with Unstable Angina/ Non-ST-Elevation Myocardial Infarction (updating the 2007 guideline): a 
report of the American College of Cardiology Foundation/American Heart Association Task Force on Practice Guidelines developed in collaboration with the American College of Emergency Physicians, Society for Cardiovascular Angiography and Interventions, and Society of Thoracic Surgeons. J Am Coll Cardiol. 2011;57(19):1920-59.

9. Schulman S, Kearon C. Subcommittee on Control of Anticoagulation of the Scientific and Standardization Committee of the International Society on Thrombosis and Haemostasis Definition of major bleeding in clinical investigations of antihemostatic medicinal products in non-surgical patients. J Thromb Haemost. 2005;3(4):692-4. https://doi.org/10.1111/j.1538-7836.2 005.01204.x.

10. Levine GN, Bates ER, Bittl JA, et al. 2016 ACC/AHA Guideline Focused Update on Duration of Dual Antiplatelet Therapy in Patients With Coronary Artery Disease: A Report of the American College of Cardiology/American Heart Association Task Force on Clinical Practice Guidelines: An Update of the 2011 ACCF/AHA/SCAI Guideline for Percutaneous Coronary Intervention, 2011 ACCF/AHA Guideline for Coronary Artery Bypass Graft Surgery, 2012 ACC/AHA/ACP/AATS/ PCNA/SCAI/STS Guideline for the Diagnosis and Management of Patients With Stable Ischemic Heart Disease, 2013 ACCF/ AHA Guideline for the Management of ST-Elevation Myocardial Infarction, 2014 AHA/ACC Guideline for the Management of Patients With Non-STElevation Acute Coronary Syndromes, and 2014 ACC/AHA Guideline on Perioperative Cardiovascular Evaluation and Management of Patients Undergoing Noncardiac Surgery. Circulation. 2016;134:123-55.

11. Matsumoto $Y$, Nakai $K$, Tsutsumi M, Iko M, Nii K, Narita S, et al. Onset time of ischemic events and antiplatelet therapy after intracranial stent-assisted coil embolization. J Stroke Cerebrovasc Dis. 2014;23(4):771-7. https://doi.org/10.1 016/j.jstrokecerebrovasdis.2013.07.008.

12. Song J, Yeon JY, Kim JS, Hong SC, Kim KH, Jeon P. Delayed thromboembolic events more than 30 days after self-expandable intracranial stent-assisted embolization of unruptured intracranial aneurysms. Clin Neurol Neurosurg. 2015;135:73-8. https://doi.org/10.1016/j. clineuro.2015.05.013.

13. Enomoto Y, Mizutani D, Yoshimura S, et al. Changing Paradigms of Periprocedural Antithrombotic Therapy in Neuroendovascular Therapy Analysis of JR-NET 3. Neurol Med Chir (Tokyo). 2019;59:247-56.

14. Stone GW, Witzenbichler B, Weisz G, Rinaldi MJ, Neumann FJ, Metzger DC, et al. Platelet reactivity and clinical outcomes after coronary artery implantation of drug-eluting stents (ADAPT-DES): a prospective multicentre registry study. Lancet. 2013;382(9892):614-23. https://doi.org/10.1016/S01406736(13)61170-8

15. Price MJ, Berger PB, Teirstein PS, Tanguay JF, Angiolillo DJ, Spriggs D, et al. Standard- vs high-dose clopidogrel based on platelet function testing after percutaneous coronary intervention: the GRAVITAS randomized trial. JAMA. 2011;305(11):1097-105. https://doi.org/10.1001/jama.2011.290.

16. Fifi JT, Brockington C, Narang J, et al. Clopidogrel resistance is associated with thromboembolic complications in patients undergoing neurovascular stenting. AJNR Am J Neuroradiol. 2013;34:721-6.

17. Kim HJ, Oh JS, Park SQ, et al. The efficacy of P2Y12 reactive unit to predict the Periprocedural thromboembolic and hemorrhagic complications according to Clopidogrel responsiveness and safety of modification of dual antiplatelet therapy: a meta-analysis. J Korean Neurosurg Soc. 2019;63:539-49.

18. Asai T, Miyachi S, Izumi T, Matsubara N, Haraguchi K, Yamanouchi T, et al. Relationship between low response to clopidogrel and periprocedural ischemic events with coil embolization for intracranial aneurysms. J Neurointerv Surg. 2016;8(7):752-5. https://doi.org/10.1136/neurintsurg-2015011727

19. Kashiwazaki D, Kuwayama N, Akioka N, Hayakawa Y, Kuroda S. The roles and issues of P2Y12 percent inhibition assessed by VerifyNow assay for patients undergoing Neurointervention: a prospective study. J Stroke Cerebrovasc Dis. 2014;23(7):1830-6. https://doi.org/10.1016/j.jstrokecerebrovasdis.2014.04. 014.

20. Kim MS, Park ES, Park JB, Lyo IU, Sim HB, Kwon SC. Clopidogrel response variability in Unruptured intracranial aneurysm patients treated with stentassisted endovascular coil embolization: is follow-up Clopidogrel response test necessary? J Korean Neurosurg Soc. 2018;61 (2):201-11. https://doi.org/1 0.3340/jkns.2017.0303.009.

21. Song J, Shin YS. Antiplatelet drug resistance did not increase the thromboembolic events after stent-assisted coiling of unruptured intracranial aneurysm: a single center experience of 99 cases. Neurol Sci. 2017;38(5):879-s885. https://doi.org/10.1007/s10072-017-2859-z.
22. Daou B, Starke RM, Chalouhi N, Barros G, Tjoumakaris S, Rosenwasser RH, et al. P2Y12 reaction units: effect on hemorrhagic and thromboembolic complications in patients with cerebral aneurysms treated with the pipeline embolization device. Neurosurgery. 2016;78(1):27-33. https://doi.org/10.122 7/NEU.0000000000000978.

23. Goh C, Churilov L, Mitchell P, Dowling R, Yan B. Clopidogrel hyper-response and bleeding risk in Neurointerventional procedures. AJNR Am J Neuroradiol. 2013;34(4):721-6. https://doi.org/10.3174/ajnr.A3418.

24. Diener HC, Bogousslavsky J, Brass LM, Cimminiello C, Csiba L, Kaste M, et al. Aspirin and clopidogrel compared with clopidogrel alone after recent ischaemic stroke or transient ischaemic attack in high-risk patients (MATCH): randomised, double-blind, placebo-controlled trial. Lancet. 2004;364(9431): 331-7. https://doi.org/10.1016/S0140-6736(04)16721-4.

25. Watanabe H, Domei T, Morimoto T, Natsuaki M, Shiomi H, Toyota T, et al. Effect of 1-month dual antiplatelet therapy followed by Clopidogrel vs 12 month dual antiplatelet therapy on cardiovascular and bleeding events in patients receiving $\mathrm{PCI}$. The STOPDAPT-2 randomized clinical trial. JAMA. 2019;321(24):2414-27. https://doi.org/10.1001/jama.2019.8145.

26. Delgado Almandoz JE, Kadkhodayan Y, Crandall BM, Scholz JM, Fease JL, Tubman DE. Variability in initial response to standard clopidogrel therapy, delayed conversion to clopidogrel hyper-response, and associated thromboembolic and hemorrhagic complications in patients undergoing endovascular treatment of unruptured cerebral aneurysms. J Neurointerv Surg. 2014;6(10):767-73. https://doi.org/10.1136/neurintsurg-2013-010976.

\section{Publisher's Note}

Springer Nature remains neutral with regard to jurisdictional claims in published maps and institutional affiliations.

Ready to submit your research? Choose BMC and benefit from:

- fast, convenient online submission

- thorough peer review by experienced researchers in your field

- rapid publication on acceptance

- support for research data, including large and complex data types

- gold Open Access which fosters wider collaboration and increased citations

- maximum visibility for your research: over $100 \mathrm{M}$ website views per year

At BMC, research is always in progress.

Learn more biomedcentral.com/submissions 